\title{
Ecological roles of the dominant bacteria from Amundsen Sea Polynya using metagenomic analysis
}

\author{
So-JEONG KIM ${ }^{1}$ \\ ${ }^{1}$ Geologic Environment Research Division, Korea Institute of \\ Geoscience and Mineral Resources, Daejeon 34132, \\ Republic of Korea, sojkim86@kigam.re.kr
}

Polynyas in the Antarctic Ocean are regions of extremely productive phytoplankton bloom, largely by Phaeocystis antarctica. Fixed carbon from primary production was actively recyled and mineralized in Amundsen Sea Polynya. Here, we described the ecological roles of the major microbial group in Amundsen Sea Polynya at peak phase of bloom using metagenomic analysis. $20 \mathrm{~L}$ seawater samples were collected by CTD samplers from chlorophyll maximum zone and genomes were reconstructed from harvested cells with metagenomic analysis. The microbial community of the polynya was dominated by three major microbes (Polaribacter, Ant4D3 clade and SAR92 clade) based on the coverage of the metagenome-assembled genome (MAGs). Polaribacter genome had (chryso)laminarin degrading gene cluster and other polysaccharide degrading loci. The chrysolaminarin was known as the storage material of Phaeocystis antarctica. The genome Ant4D3 clade had genes for utilizing low molecular weight (LMW) organic matters, such as amino acids, mono- and disccharides. SAR92 clade had a potnetial for growth using both polysaccharide and LMW organic matters. Our results provide insight into niches of key heterotrophic populations related to microbial loop in Antarctic waters. 